\title{
A Constitucionalidade do Projeto Mais Médicos para o Brasil
}

\author{
Constitutionality of the More Doctors to Brazil Program \\ Constitucionalidad del Proyecto Más Médicos para el Brasil
}

Janaina Pontes Cerqueira ${ }^{1}$

Sandra Mara Campos Alves ${ }^{2}$

RESUMO: A escassez de profissionais médicos em determinadas áreas no Brasil é tema que sempre mereceu atenção especial do Estado. O Projeto Mais Médicos para o Brasil, implementado por meio da Medida Provisória no 621, de 8 de julho de 2013, autoriza a atuação de médicos estrangeiros sob regime especial de aperfeiçoamento profissional no Sistema Único de Saúde (SUS), na Atenção Básica, possibilitando a cobertura médica assistencial em regiões prioritárias e vulneráveis do país. Porém foi fruto de questionamento judicial junto ao Supremo Tribunal Federal, por meio de ação direta de inconstitucionalidade, que colocou em confronto os limites constitucionais de autorização para essa forma de atuação profissional. O estudo objetivou identificar os argumentos jurídicos utilizados pelos diversos atores que atuaram nas ADINs 5035-DF e 5037-DF, notadamente no que se refere ao Projeto Mais Médicos para o Brasil, ajuizadas no Supremo Tribunal Federal e analisá-los à luz da Teoria dos Direitos Fundamentais de Robert Alexy. Os resultados apontam que o Projeto, na sua estruturação legal, encontra legitimidade na medida em que não se confunde com a abertura de mercado de trabalho, institui regime específico de atuação profissional, com garantias essenciais dos indivíduos, atenta para diretrizes de cooperação internacional em saúde da Organização Mundial de Saúde (OMS) e demonstra eficácia social com a concreta ampliação de acesso da população na cobertura assistencial até que medidas conjunturais e estruturantes da formação médica no Brasil sejam implementadas e alcancem resultados diretos à população usuária do SUS.

Palavras-chave: Projeto Mais Médicos para o Brasil. Constitucionalidade. Recursos Humanos em Saúde. Direito à Saúde.

\begin{abstract}
The shortage of medical professionals in certain areas of Brazil is a subject that has always deserved special attention from the State. The More Physicians for Brazil Project, implemented by the Provisional Measure \#621, of $8^{\text {th }}$ of July, 2013, authorized the work of foreign doctors in Brazil under the special regime for professional development in the Unified Health System (UHS), and was subject to legal challenging from the Federal Supreme Court by means of direct action of unconstitutionality, especially in Primary Healthcare, enabling medical assistance coverage in priority and vulnerable regions of the country, but which questioned the constitutional permit limits for

\footnotetext{
${ }_{1}^{1}$ Assess ora do Ministério da Saúde. Secretaria de Gestão do Trabalho e da Educação na Saúde. Gabinete. Brasília Distrito Federal.Brasil.E-mail:janaina.cerqueira@saude.gov.br

2 Advogada, Doutoranda em Saúde Pública e Mestre em Políticas Sociais pela Universidade de Brasília, Brasil. Pesquisadora-colaboradora da Fundação Oswaldo Cruz-Fiocruz, Brasil. Membro titular da Rede Ibero-Americana de Direito Sanitário.
} 
this type of professional activity. This study had as aim to identify the legal arguments utilized by a diverse set of players concerning ADINs \#5035-DF and \#5037-DF, notably with regards to the More Physicians for Brazil Project, both filed in the Federal Supreme Court, and analyze these in the light of Robert Alexy's Theory of Fundamental Rights. The results show that the Project, in its legal structure, finds legitimacy in that it cannot be mistaken with the opening of the labor market, establishes a specific regime for professional activity, with essential guarantees for individuals, considers the World Health Organization (WHO) international cooperation guidelines in health, and demonstrates social effectiveness with the concrete expansion of public access to healthcare coverage until cyclical and structural measures of medical education in Brazil are implemented and achieve direct results to the population user of the UHS.

Keywords: Project More Doctors to Brazil; Constitutionality; Human Resources for Health; Right to Health.

RESUMEN: La escasez de profesionales médicos en áreas lejanas del Brasil es un tematica que siempre ha merecido atención especial del Estado. El Proyecto Más Médicos para el Brasil (Medida Provisional № 621, de 08 de julio 2013), autorizó el trabajo de médicos extranjeros en Brasil bajo régimen especial para el desarrollo profesional en el Sistema Unico de Salud (SUS). Hubo un cuestionamiento judicial por parte de la Corte Supremo Federal por medio de cuestión de inconstitucionalidad, especialmente en Atención Primaria de Salud, posibilitó la cobertura de la asistencia médica en regiones prioritarias y vulnerables del país, pero cuestionó los límites constitucionales de permisión para esta actividad profesional. Este estudio tuvo como objetivo la discusión de las argumentaciones jurídicas de los personajes que trabajaran en las ADIN № 5035-DF y № 5037-DF, en particular no que se refiere al Proyecto Más Médicos para el Brasil, presentadas en la Corte Suprema Federal, y analizar éstos a la luz de la Teoría de los Derechos Fundamentales de Robert Alexy. Los resultados demuestran que el Proyecto, en su estructura legal, encuentra legitimidad que no puede confundirse con la apertura del mercado de trabajo, establece un régimen específico para la actividad profesional, con garantías esenciales para las personas, considera los lineamientos de cooperación internacional de la Organización Mundial de la Salud (OMS), y demuestra la eficacia social con la expansión concreta del acceso público a la cobertura de salud.

Palabras-llave: Proyecto Más Médicos para el Brasil; Constitucionalidad; Recursos Humanos en Salud; Derecho a la Salud.

\section{Introdução}

A assistência médica em saúde é fonte de preocupação mundial e objeto de permanente mapeamento pela Organização Mundial de Saúde (OMS), especialmente quanto ao contingente e distribuição do profissional médico nos países e suas regiões internas. No ano de 2012, o relatório das Estatísticas Mundiais em Saúde da OMS (1) ao realizar o levantamento numérico de médicos por mil habitantes dos países do globo a 
ela filiados, diagnosticou o quantitativo de 1,86 médicos por mil habitantes no Brasil, ao passo que países como o Uruguai e a Argentina, para citar a América do Sul, destacando-se as dimensões territoriais, apresentavam números de 3,16 e 3,74 respectivamente. E países com sistemas públicos de saúde similares ao Brasil apresentaram índices distributivos de 3,9 (Portugal), 4 (Espanha) e 2,7 (Inglaterra).

No Brasil, essa preocupação encontrou reforço, mobilizando o Ministério da Saúde, a partir de pesquisa promovida pelo Conselho Federal de Medicina (CFM) em conjunto com o Conselho Regional de Medicina do Estado de São Paulo (CREMESP), no ano de 2011, sobre Demografia Médica (2) com os seguintes apontamentos: a) a distribuição de médicos no Brasil reforça a desigualdade no país; b) a presença de médicos nas capitais é duas vezes maior que a média nacional; c) embora seja grande o número de médicos no Brasil, não é suficiente para a demanda assistencial da população; d) os usuários do SUS têm quatro vezes menos médicos que os do setor privado; e) há desigualdade na distribuição de médicos entre os setores público e privado, sendo este mais atrativo ao profissional. Ainda segundo a pesquisa:

Das 27 unidades da federação, 22 estão abaixo da média nacional, sendo que cinco, todas nas regiões norte e nordeste, têm o inaceitável indicador de menos de $1 \mathrm{med} / 1000 \mathrm{hab}$. Até mesmo o Estado de São Paulo, que detém a $3^{\text {a }}$ melhor média nacional (2,49 med./1000 hab.), tem apenas seis de seus 17 departamentos regionais de saúde com média acima da nacional (2).

Esses dados vieram a corroborar o que a gestão do SUS e a sociedade apontavam como um dos graves problemas da saúde no Brasil, o déficit de cobertura médica, a desigual distribuição desses profissionais no território nacional, com alta concentração nas capitais e regiões metropolitanas, em especial nas Regiões Sudeste e Sul, e com perfil de busca pela especialização profissional, o que indica escassez de médicos com atuação voltada a Atenção Primaria em Saúde, ou, como denominada no SUS, Atenção Básica.

Nesse sentido, o Conselho Nacional de Saúde, instância máxima do SUS, recomendou através da na Resolução n 439, de 07 de abril de 2011(3) a necessidade de atuação das três esferas federativas para garantir que a Rede de Atenção Básica, inclusa ou não a estratégia de saúde da família, fosse efetivada como a principal porta 
de entrada do SUS, com acolhimento humanizado, atenção integral resolutiva, equânime e multiprofissional e com condições de garantir o cuidado ao usuário e preconizando a intensificação de esforços e criação de novas políticas para "garantir profissionais de saúde em todas as regiões e localidades do país, principalmente as mais vulneráveis e de difícil acesso, universalizando de fato o direito à saúde", o que ensejaria a presença essencial do profissional médico em atuação nas unidades básicas de saúde.

Segundo pesquisa sobre a percepção social do SUS realizada pelo Instituto de Pesquisas Aplicadas (IPEA) em 2011, para 58\% dos entrevistados a medida mais importante a ser tomada no SUS era o aumento do número de médicos nos serviços de saúde (4).

Em suma, conforme Heider et al, 2014 (5), as regiões mais pobres, de difícil acessibilidade, com elevado componente de violência social e precárias condições econômicas, sociais e sanitárias são as que mais carecem e mais padecem da assistência de profissional médico e as que mais exigem, ainda, a cobertura da assistência básica em saúde.

O Poder Executivo Federal instituiu, no ano de 2013, por meio da Medida Provisória no 621, de 08 de julho (6), convertida na Lei ํㅜ 12.871, de 22 de outubro de 2013 (7), o Programa Mais Médicos com a finalidade de formar recursos humanos na área médica para o SUS e com objetivo, dentre outros, de diminuir a carência de médicos nas regiões prioritárias para o SUS, a fim de reduzir as desigualdades regionais na área da saúde, este através do Projeto Mais Médicos para o Brasil.

Nesse sentido, o Projeto Mais Médicos para o Brasil se constitui como estratégia para provisão de médicos na Atenção Básica em regiões prioritárias para o SUS, possibilitando o aumento da cobertura assistencial imediata à população destas localidades, em apoio às gestões municipais, até que se implemente no Brasil os objetivos de formação de contingente médico em patamar que supere 0 déficit assistencial, e foi objeto de regulamentação nos termos da Portaria Interministerial $n^{0}$ 1.369/MS/MEC, de 8 de julho de 2013 (8).

Para a fixação dos médicos nas regiões vulneráveis, o Projeto estabelece como critério essencial a seguinte ordem de prioridade de acesso à participação (8): 
a) ao profissional formado em instituição de educação superior brasileira ou com diploma revalidado no Brasil (ou seja, o profissional que tem plena autorização para o exercício da medicina no Brasil) devendo possuir inscrição no órgão de classe;

b) em seguida, o acesso pelo brasileiro, com formação em instituição de educação superior estrangeira, com habilitação para exercício da medicina na forma da lei do respectivo país (aqui, prestigia-se a nacionalidade);

c) e, por fim, em caráter residual de acesso, o estrangeiro formado em instituição de educação superior estrangeira, com habilitação para exercício da medicina na forma da lei do respectivo país.

O Projeto estabelece ainda um parâmetro de acessibilidade aos profissionais com formação e habilitação médica no exterior apenas em países que apresentem índice de relação estatística de médico por mil habitantes segundo Estatísticas Mundiais em Saúde igual ou superior a 1,8 (1) com finalidade de garantir o não agravamento do "déficit" de profissionais médicos em determinados países para atender recomendações do Código Global de Práticas para Recrutamento Internacional de Profissionais da Saúde da Organização Mundial da Saúde (9).

Ademais, no tocante à atuação dos profissionais estrangeiros, o Projeto condiciona o acesso à declaração de conhecimento da língua portuguesa e a submissão à avaliação quanto a esse conhecimento, sob pena de impossibilidade de participação (8).

Quanto à adesão dos municípios, a Portaria o. 1.369/2013/MS/MEC (8) definiu perfis de vulnerabilidade e de elegibilidade, de modo a estabelecer prioridades de alocação de profissionais, bem como a delimitação e autorização de vagas, conjugando critérios estabelecidos pela Portaria №. 1.377/GM/MS, de 13 de junho de 2011(10) e dados do Sistema do Cadastro de Estabelecimentos de Saúde (SCNES) (11) que apontam déficit ocupação das vagas de médicos nas equipes das unidades de básicas de saúde.

Por fim, com o referencial numérico da pesquisa do CFM (2), o Projeto (8) previu como necessária a cooperação internacional para recrutamento de médicos para atuação da Atenção Básica, em intercâmbio, como medida de fortalecimento das Redes de Atenção à Saúde no Brasil, segundo preconizam mandatos da Organização das Nações Unidades para os sistemas de saúde, como informa Molina et al, 2014 (12). 
A República Federativa do Brasil, através do Ministério da Saúde, celebrou com a Organização Pan-Americana de Saúde (Opas/OMS) o Termo de Cooperação № 80 com vistas ao "Fortalecimento da Atenção Básica no Brasil" e respectivos Termos Ajuste voltados à "Ampliação do Acesso da População Brasileira à Atenção Básica em Saúde", por meio do qual, em colaboração com a República de Cuba e o Ministério da Saúde Pública de Cuba, foi possível o recrutamento de médicos cubanos para migração e inserção em aperfeiçoamento em milhares de municípios brasileiros mais vulneráveis e que não interessaram à adesão por médicos brasileiros, nem aos médicos estrangeiros recrutados por processo de seleção pública.

Lançado o Programa Mais Médicos em julho de 2013, ao final do mês de agosto do mesmo ano, foram propostas duas ações diretas de inconstitucionalidade (ADINs 5035DF e 5037-DF) (13) (14) questionando a Medida Provisória nº 621/2013 cujo enfrentamento afetaria, por inclusão, o Projeto Mais Médicos para o Brasil.

O pedido de liminar foi negado pelo Ministro Relator, e as ações ainda não foram julgadas de forma definitiva. Contudo, conhecer os argumentos utilizados pelas partes para condenar ou defender o Projeto é matéria de interesse do direito sanitário, uma vez que aborda o tema da escassez de médicos no Brasil, da necessária provisão de cobertura assistencial médica a população mais carente, como garantia do direito à saúde e da universalidade do SUS, e da legitimidade da autorização para atuação de médicos estrangeiros, sem abertura plena do mercado.

Este artigo objetivou identificar os argumentos jurídicos utilizados pelos atores principais das ADINs 5035-DF e 5037-DF, pontualmente quanto ao Projeto Mais Médicos para o Brasil, ajuizadas no Supremo Tribunal Federal e analisá-los à luz da Teoria dos Direitos Fundamentais de Robert Alexy (15) e sua confluência com o conceito de direito como integridade em Ronald Dworkin (16) de modo a levantar elementos indicativos de constitucionalidade pela prevalência dos princípios afeitos ao direito à saúde e progresso da humanidade.

\section{Metodologia}

Tratou-se de pesquisa descritivo-analítica, de caráter documental. Foram analisadas as peças processuais constantes nas ADINs 5035-DF e 5037-DF, 
disponíveis no sítio eletrônico do STF (www.stf.jus.br/consultaprocessual), a saber: a) petições iniciais; b) defesa da União; c) peças de defesa do ato normativo pelo Poder Legislativo, através de suas Casas, e d) pareceres da Procuradoria Geral da República, extraindo delas os elementos pertinentes aos direitos e princípios constitucionais invocados, agrupando os pontos comuns de argumentação.

De forma complementar, foi feita revisão bibliográfica hermenêutica da literatura acadêmico-científica sobre a ponderação de princípios constitucionais segundo a Teoria dos Direitos Fundamentais de Robert Alexy (15) e a Teoria da Integridade do Direito de Dworkin (16), além do estudo de artigos publicados sobre o Programa Mais Médicos, dentro qual se insere o Projeto Mais Médicos para o Brasil, como mecanismo de aperfeiçoamento e provisão de profissionais médicos, inclusive mediante cooperação técnica internacional, utilizando estes descritores.

\section{Resultados}

As ADINs foram ajuizadas pela Associação Médica Brasileira (AMBR), Conselho Federal de Medicina (CFM) e Confederação Nacional dos Trabalhadores Liberais Universitários (CNTU). Especialmente sobre o Projeto Mais Médicos para o Brasil, as entidades proponentes pleitearam em caráter liminar a suspensão de eficácia das seguintes normas da Medida Provisória n. 621/2013, artigo 7º, nos incisos I e II,

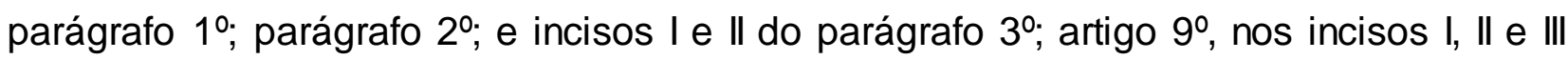
do parágrafo 1ㅇ; artigo 10, nos parágrafos $1^{\circ}, 2^{\circ}$, $3^{\circ}$ e $4^{\circ}$; e artigo 11 e, no mérito, a declaração de inconstitucionalidade.

Os artigos se referem especificamente à autorização do exercício da medicina por profissional estrangeiro sem revalidação do diploma.

Em defesa do ato impugnado manifestaram-se a União, através da Advocacia Geral da União (17), a Câmara dos Deputados (18) e o Senado Federal (19), estes dois conforme Notas de suas respectivas Consultorias Legislativas.

A Procuradoria Geral da República (20) também se manifestou pela constitucionalidade do Programa e, portanto, do Projeto Mais Médicos para o Brasil

$\mathrm{Da}$ análise dos documentos foi possível estabelecer um quadro comparativo que apresenta sinteticamente os principais argumentos levantados pelos diversos atores que 
aturaram nas ADINs 5035-DF e 5037-DF, relacionado ao Projeto Mais Médicos para o Brasil, dispostos no quadro 1.

Quadro 1 - Comparativo dos direitos, garantias e princípios constitucionais apontados pelos diversos atores que aturaram nas ADINs 5035-DF e 5037-DF, para ataque e defesa da Medida Provisória n. 621/2013 no que se refere ao Projeto Mais Médicos para o Brasil.

\begin{tabular}{|c|c|c|c|c|}
\hline \multirow{2}{*}{$\begin{array}{c}\text { DIREITOS } \\
\text { GARANTIAS e } \\
\text { PRINCÍPIOS CF/88 }\end{array}$} & \multicolumn{4}{|c|}{ ATORES } \\
\hline & $\begin{array}{l}\text { AMBR } \\
\text { CFM e } \\
\text { CNTU }\end{array}$ & UNIÃO & $\begin{array}{l}\text { CAMARA DOS } \\
\text { DEPUTADOS e } \\
\text { SENADO }\end{array}$ & $\begin{array}{l}\text { PROCURADORIA } \\
\text { GERAL DA } \\
\text { REPÚBLICA }\end{array}$ \\
\hline $\begin{array}{l}\text { * Devido Processo } \\
\text { Legislativo: urgência } \\
\text { e relevância } \\
\text { (Art. } 62 \text {, caput) }\end{array}$ & 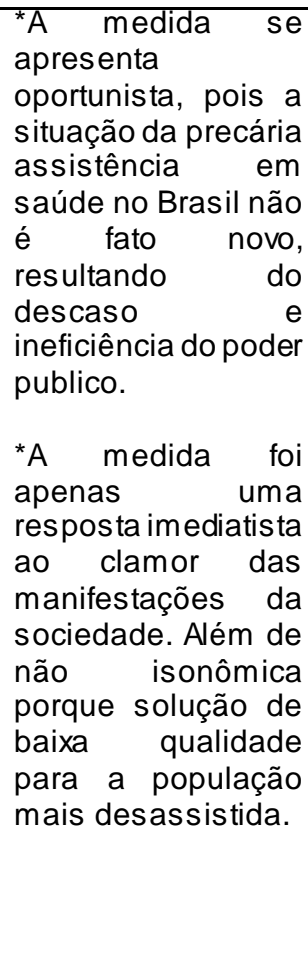 & $\begin{array}{l}\text { * Princípio da } \\
\text { universalidade do } \\
\text { acesso ao SUS } \\
\text { (Arts. 196 e 198, } \\
\text { II). } \\
{ }^{*} \text { Redução das } \\
\text { desigualdades } \\
\text { sociais na } \\
\text { garantia da } \\
\text { assistência à } \\
\text { saúde (Arts. } 3^{\circ} \text {, I e } \\
\text { III, } 5^{\circ}, 6^{\circ} \text { e arts. } \\
\text { 196 e 198). } \\
\text { *São } \\
\text { relevância pública } \\
\text { as ações e saúde: } \\
\text { serviços } \\
\text { saúde: Art. 197. } \\
\text { *Competência do } \\
\text { Poder Executivo, } \\
\text { como gestor do } \\
\text { SUS, para } \\
\text { ordenara } \\
\text { formação de } \\
\text { recursos humanos } \\
\text { em saúde (Art. } \\
\text { 200, III). }\end{array}$ & 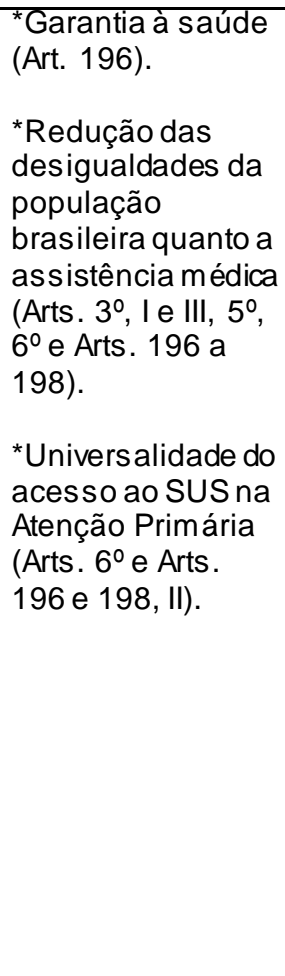 & $\begin{array}{l}{ }^{*} \text { Relevância pela } \\
\text { comprovação pelos } \\
\text { dados alarmantes de } \\
\text { precariedade do } \\
\text { atendimento médico } \\
\text { em milhares de } \\
\text { municípios brasileiros } \\
\text { (Art. 62, caput). } \\
{ }^{*} \text { Garantia do direito à } \\
\text { saúde (Art. 6\%). } \\
\text { *Universalidade do } \\
\text { SUS (Arts. 196 e 198, } \\
\text { II). }\end{array}$ \\
\hline 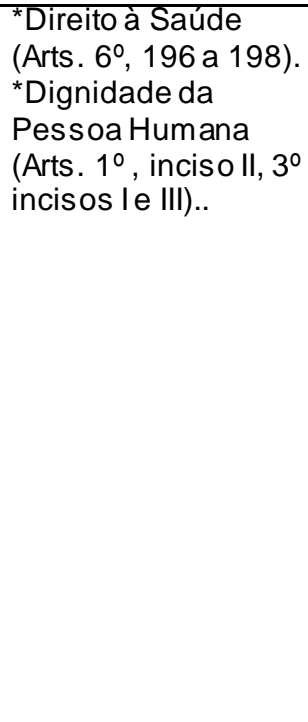 & $\begin{array}{l}\text { *Duvidosa qualidade } \\
\text { dos serviços } \\
\text { médicos prestados } \\
\text { por profissionais } \\
\text { estrangeiros. } \\
\text { *Violação aos } \\
\text { princípios da } \\
\text { isonomia e ao } \\
\text { tratamento } \\
\text { igualitário vez que a } \\
\text { população será } \\
\text { atendida por "não } \\
\text { médicos", segundo } \\
\text { a legislação } \\
\text { brasileira. }\end{array}$ & $\begin{array}{l}{ }^{*} \text { Alei adota } \\
\text { parâmetros } \\
\text { objetivos, } \\
\text { inclusive } \\
\text { preconizados pela } \\
\text { OMS para a } \\
\text { seleção dos } \\
\text { profissionais. } \\
\text { Exigência legal } \\
\text { mínima de que } \\
\text { sejam } \\
\text { efetivamente } \\
\text { formados em } \\
\text { medicina e } \\
\text { possuam } \\
\text { habilitação para o } \\
\text { exercício da } \\
\text { profissional, } \\
\text { segundo as } \\
\text { normas de seus }\end{array}$ & $\begin{array}{l}{ }^{*} \text { A lei estabeleceu } \\
\text { parâmetros } \\
\text { objetivos quanto à } \\
\text { formação e } \\
\text { habilitação para } \\
\text { exercício da } \\
\text { medicina para } \\
\text { atuação dos } \\
\text { médicos } \\
\text { estrangeiros. } \\
\text { *Fiscalização pelo } \\
\text { Poder Executivo e } \\
\text { pelo CFM. } \\
\text { ^Os profissionais } \\
\text { atuam em } \\
\text { aperfeiçoamento, } \\
\text { sob regime de } \\
\text { supervisão por } \\
\text { médicos } \\
\text { brasileiros. }\end{array}$ & $\begin{array}{l}{ }^{*} \text { Adoção de critérios } \\
\text { objetivos para a } \\
\text { seleção dos médicos } \\
\text { estrangeiros, com } \\
\text { exigência mínima } \\
\text { essencial de que } \\
\text { sejam efetivamente } \\
\text { formados em } \\
\text { medicina e possuam } \\
\text { habilitação para o } \\
\text { exercício da } \\
\text { profissional, segundo } \\
\text { as normas de seus } \\
\text { países. } \\
\text { ^Avaliação quanto ao } \\
\text { conhecimento escrito } \\
\text { e verbal da língua } \\
\text { portuguesa. } \\
{ }^{\star} \text { A camada } \\
\text { populacional sequer }\end{array}$ \\
\hline
\end{tabular}




\begin{tabular}{|c|c|c|c|c|}
\hline & & países. & & $\begin{array}{l}\text { tem acesso a } \\
\text { atendimento médico. } \\
{ }^{\star} \mathrm{A} \text { isonomia revela-se } \\
\text { na medida em que } \\
\text { propicia concretizar } \\
\text { esse mínimo direito } \\
\text { assistencial. }\end{array}$ \\
\hline $\begin{array}{l}\text { *Concurso Público } \\
\text { (Art. } 37 \text {,inciso I) }\end{array}$ & $\begin{array}{l}\text { * Burla ao princípio } \\
\text { constitucional do } \\
\text { concurso público, da } \\
\text { moralidade e } \\
\text { impessoalidade, } \\
\text { travestindo de } \\
\text { especialização a } \\
\text { atuação na } \\
\text { prestação em si do } \\
\text { serviço médico, } \\
\text { mediante } \\
\text { pagamento com } \\
\text { recurso público. }\end{array}$ & $\begin{array}{l}{ }^{*} \text { P Projeto não } \\
\text { disponibilizou } \\
\text { acesso a cargo ou } \\
\text { emprego público. } \\
{ }^{\star} \text { A moralidade e } \\
\text { impessoalidade } \\
\text { encontram tutela } \\
\text { legal no processo } \\
\text { de seleção } \\
\text { pública dos } \\
\text { médicos e de } \\
\text { recrutamento por } \\
\text { instrumento de } \\
\text { cooperação } \\
\text { internacional, com } \\
\text { dever de } \\
\text { observância aos } \\
\text { requisitos } \\
\text { normativos de } \\
\text { participação. }\end{array}$ & $\begin{array}{l}{ }^{*} \text { Acesso ao Projeto } \\
\text { por seleção } \\
\text { pública ou } \\
\text { cooperação } \\
\text { internacional (Arts. } \\
3^{\circ} \text {, inciso IX, } 7^{\circ}, \S \\
3^{\circ}, 9^{\circ} \text { e } 17 \text { ) para } \\
\text { regime especial de } \\
\text { atuação em } \\
\text { modalidade de } \\
\text { aperfeiçoamento } \\
\text { profissional, não } \\
\text { havendo } \\
\text { disponibilização de } \\
\text { cargo ou emprego } \\
\text { público. }\end{array}$ & $\begin{array}{l}\text { *O mesmo princípio } \\
\text { que tutela o livre } \\
\text { exercício da profissão, } \\
\text { autoriza o indivíduo a } \\
\text { poder exercitá-la para } \\
\text { fins de } \\
\text { aperfeiçoamento } \\
\text { (especialização), sob } \\
\text { regime de atuação } \\
\text { específica e } \\
\text { supervisionado. Fosse } \\
\text { trabalho, não estaria } \\
\text { sob supervisão } \\
\text { acadêmica (Art. 5o, } \\
\text { XIII). }\end{array}$ \\
\hline $\begin{array}{l}\text { *Prevalência dos } \\
\text { Direitos Humanos e } \\
\text { da Cooperação entre } \\
\text { os povos para o } \\
\text { progresso da } \\
\text { humanidade (Art. } 4 \stackrel{\circ}{ } \\
\text { incisos II e IX). } \\
\text { Direitos Sociais à } \\
\text { Saúde e ao Trabalho } \\
\text { (Arts. } 6^{\circ} \text { e } 7^{\circ} \text { ). }\end{array}$ & $\begin{array}{l}\text { *Violação aos } \\
\text { direitos trabalhistas, } \\
\text { criando "verdadeira } \\
\text { escravidão } \\
\text { disfarçada de } \\
\text { intercâmbio". } \\
\text { Sem tutela dos } \\
\text { direitos trabalhistas } \\
\text { constitucionais e } \\
\text { inobservância dos } \\
\text { tratados } \\
\text { internacionais } \\
\text { trabalhistas. }\end{array}$ & $\begin{array}{l}\text { *Atuação } \\
\text { profissional sem } \\
\text { vínculo } \\
\text { empregatício. } \\
\text { *Trata-se de } \\
\text { aperfeiçoamento } \\
\text { profissional e não } \\
\text { disponibilização } \\
\text { de cargo ou } \\
\text { emprego público } \\
\text { sob o que não } \\
\text { incide a regra de } \\
\text { concurso público } \\
\text { e nem os direitos } \\
\text { fundamentais da } \\
\text { proteção a } \\
\text { relação de } \\
\text { emprego. }\end{array}$ & $\begin{array}{l}\text { *Trata-se de } \\
\text { aperfeiçoamento } \\
\text { profissional e não } \\
\text { disponibilização de } \\
\text { cargo ou emprego } \\
\text { público. Livre } \\
\text { exercício da } \\
\text { profissão: art. 5ํ, } \\
\text { XIII. }\end{array}$ & $\begin{array}{l}\text { *A lei instituidora do } \\
\text { PMMB possibilita o } \\
\text { exercício da profissão } \\
\text { para fins de através } \\
\text { de um programa de } \\
\text { aperfeiçoamento. } \\
\text { *Não cabe abordar } \\
\text { acerca de violação de } \\
\text { direitos trabalhistas, } \\
\text { ou violação de pactos } \\
\text { internacionais pois } \\
\text { não há criação de } \\
\text { cargo ou emprego } \\
\text { público. O exercício } \\
\text { de função pública, } \\
\text { inclusive em caráter } \\
\text { excepcional e } \\
\text { temporário é } \\
\text { constitucionalmente } \\
\text { autorizado na forma } \\
\text { da lei. }\end{array}$ \\
\hline
\end{tabular}

Fonte: Elaborado pela autora com base nas peças processuais que compõem as ADINs 5035-DF e 5037-DF disponíveis no sítio eletrônico do STF.

\section{Discussão}

Observa-se dos resultados levantados que é sob a perspectiva de eventual conflito entre regras instituídas pelo Poder Executivo e pelo Poder Legislativo, assentadas nos princípios constitucionais do direito à saúde e da universalidade do SUS, e os princípios constitucionais afetos aos direitos sociais ao trabalho e princípios de cooperação 
internacional que gravita a discussão jurídico-constitucional sobre o Projeto Mais Médicos para o Brasil através das ADIN's 5035-DF e 5037-DF.

A análise dos argumentos apresentados nas ações de inconstitucionalidade norteia-se pela Teoria dos Direitos Fundamentais de Alexy (15), que parte da distinção entre regras e princípios para que se alcance critérios de garantia de direitos fundamentais quando princípios constitucionais sejam conflitantes.

Alexy (15) delineia o sistema de normas constitucionais como de regras e princípios, sob a premissa de que ambos constituem comandos a serem cumpridos em definitivo pelos indivíduos, por si e pela coletividade e, principalmente, pelo Estado, enquanto Poder Público. De um lado, através dos Poderes Legislativo e Executivo como agentes estatais promotores desse patrimônio, mediante edição e execução de leis. De outro, por meio do Poder Judiciário como agente propulsor do equilíbrio no conflito de tais garantias e na sobreposição do indivíduo e da coletividade às limitações estatais.

Assim, para solução de conflitos entre direitos, garantias e princípios constitucionais, a Teoria dos Direitos Fundamentais de Alexy (15) começa por distinguir (a) as regras como implicadoras da desvinculação do Estado à sua disponibilização; e (b) os princípios como passíveis de concretização pelo Estado em diversos graus, dependendo da disponibilidade dos meios necessários à sua implementação.

As regras consubstanciariam uma decisão política, portanto, consideram conjunturas, reivindicações e exigem a realização mais ampla possível, de acordo com as possibilidades fáticas e jurídicas, do que resultam três consequências importantes segundo Alexy (15): a) se uma ação fora adequada para promover a realização de um princípio, mas não for adequada para promover a realização de outro, então haverá a preponderância de um sobre o outro; b) além disso, se houver uma alternativa que promova a realização de um dos princípios e iniba menos o outro deverá, então ser escolhida; c) por fim, quanto maior for o grau de afetação de um princípio, maior tem que ser a importância do cumprimento do outro. Tais diretrizes correspondem à máxima proporcionalidade na avaliação das regras frente aos princípios.

Sob tal sentido, a Teoria dos Direitos Fundamentais de Alexy (15) revela-se como base jurídica indicadora da legitimidade constitucional na atuação dos Poderes Executivo e Legislativo em instituir a política pública emergencial de recursos humanos 
em saúde através do Projeto Mais Médicos para o Brasil, sob a vertente interpretativa de que "as condições sob as quais um princípio prevalece sobre outro, formam o suposto de fato de uma regra que determina as consequências jurídicas do princípio prevalecente". Na regra Projeto Mais Médicos para o Brasil, os princípios da dignidade da pessoa humana e da universalidade do SUS, projeções do direito à saúde.

Também pela perspectiva teórica da Integridade do Direito de Dworkin (16), segundo a qual "(...) o cânone interpretativo do direito como integridade é exatamente o pilar de equidade e justiça, baseado no sistema de princípios justificadores de determinada decisão no tempo de propagação" pode-se alcançar o indicativo de constitucionalidade do Projeto como decisão política que confere plenitude ativa ao direito fundamental à saúde sob o aspecto do princípio da universalidade do SUS e da redução das desigualdades sociais. A integridade, para Dworkin (16) constitui um ideal político na medida em que ele considera a comunidade política como uma comunidade de princípios.

Ainda que com visões diversas sobre interpretação constitucional, a Teoria da Integridade do Direito dialoga com a Teoria dos Direitos Fundamentais, no contexto da ação programática do Projeto (como ideal político), na medida em que ambas possibilitam sublimar os princípios da dignidade da pessoa humana e da universalidade do SUS, ínsitos ao direito à saúde, em detrimento de eventuais princípios de caráter laboral, o que legitima a atuação dos Poderes Executivo e Legislativo valorá-lo a menor sob o primado do benefício coletivo. No dizer de Dworkin (16), assentados tais Poderes na equidade e justiça; no dizer de Alexy (15) acentuando o grau de um princípio constitucional em detrimento de outro, conforme valores essenciais à sociedade em dado tempo e conjuntura.

E essa prevalência principiológica e, portanto, legitimidade constitucional, se mostra, sob direcionamento de tais teorias, pelo aspecto da urgência e relevância, como pela excepcional autorização da atuação do médico estrangeiro no Brasil, inclusive quanto ao uso da cooperação técnica internacional, mediante aperfeiçoamento profissional como mecanismo de provisão e pronta garantia do direito à assistência médica em saúde aos indivíduos alocados em áreas deficitárias do Brasil, fazendo cumprir os princípios constitucionais do SUS da universalidade, isonomia na cobertura 
médica e ordenação de recursos humanos em saúde que suplantam a suposta violação aos princípios igualmente constitucionais dos direitos sociais do trabalho e do concurso público.

No que tange à cooperação internacional para ações voltadas à tutela da saúde sob o aspecto da assistência médica, cabe recordar que suas bases remontam a Declaração Universal dos Direitos Humanos (21) nos termos do artigo 25ํㅜ e assento na Constituição Federal do Brasil (22), apresentando expressão inconteste e fundante nos princípios das relações internacionais pela República Federativa do Brasil da prevalência dos direitos humanos e da cooperação entre os povos para o progresso da humanidade (art. 4ํㅜ ,I e IX), ao que se integram os objetivos de construir uma sociedade livre, justa e solidaria e da erradicação da pobreza e da marginalidade e redução das desigualdades sociais e regionais (art. 3ำ I e III).

A integração entre Estados voltada ao progresso da humanidade e redução de iniquidades na saúde encontra assento na Declaração sobre Atenção Primária à Saúde (APS), assinada na Conferência Internacional realizada em Alma Ata, em 1978 (23), colocando a saúde como direito humano fundamental e preconizando aos Estados alterações técnicas e políticas, além de mudanças na alocação. Tal integração se desenvolve, no âmbito das Américas, através da Cooperação Sul-Sul (CSS) (24) que objetiva o intercâmbio de experiências em saúde, por meio de compartilhamento de conhecimento, tecnologia, recursos humanos, transferência institucional de capacidades operacionais e regulatórias para a promoção de autossuficiência nacional.

Ademais, no âmbito da ordem jurídica interna, o Decreto Legislativo no 11, de 23 de fevereiro de 1956 autoriza o Convênio Básico entre o Brasil e a OMS (25), e o Decreto $n^{\circ}$ 3.594, de 8 de setembro de 2000 que prevê o Ajuste Complementar ao Convênio Básico entre o Brasil e a OMS e o Acordo entre o Governo da República Federativa do Brasil e a Repartição Sanitária Pan-Americana da Saúde (26).

O exame das regras normativas do Projeto Mais Médicos para o Brasil, na medida em que consubstanciam um especial regime de tutela ao usuário do SUS e de formação profissional para atuação no SUS, com foco na Atenção Básica em Saúde, aponta integral conformidade ao que Alexy (15) teorizou como regra essencial ao tratamento 
dos conflitos de direitos fundamentais: "Quanto maior for o grau de satisfação de um princípio, tanto maior terá a importância de satisfação do outro".

Sob tal diretriz, pode-se compreender que os mesmos artigos da Constituição apontados como violados pelo Projeto Mais Médicos para o Brasil, são as regras que fornecem a base jurídica essencial a respaldá-lo, inclusive e notadamente quanto ao aspecto do recrutamento de médicos estrangeiros mediante cooperação internacional.

Identifica-se esse respaldo sob as diretrizes constitucionais do princípio da universalidade que rege o SUS (art. 196) e do imperativo de garantia do direito à saúde (art. 6º), da inexistência de cargo ou emprego público (art. 37, II e IX) e, portanto, de vínculo laboral entre os profissionais recrutados e a União (arts. 6ํㅜ e 7ํํ), e da redução das desigualdades regionais e da cooperação internacional entre os povos para o progresso da humanidade (arts. $1^{\circ}$, III, $3^{\circ}$, III e $4^{\circ}, \mathrm{IX}$ ).

Depreende-se, a partir da Teoria dos Direitos Fundamentais de Alexy (15), e ainda sob a Teoria da Integridade do Direito, em Dworkin (16) que o assentamento normativo do Projeto Mais Médicos para o Brasil consubstancia exercício de competência pelo Governo Brasileiro do dever prestacional do direito à saúde pelo Estado, sob o aspecto da assistência médica ao indivíduo, ao estabelecer regras que viabilizam concretizar princípios constitucionais e legais da Ordem Jurídica Brasileira sobre o SUS.

\section{Conclusão}

O Poder Público brasileiro, ao pretender concretizar o princípio da universalidade, basilar ao SUS, instrumentalizando-o, em caráter emergencial e excepcional, sob um determinado aspecto da garantia de recurso humano essencial em saúde, qual seja o profissional médico, assegura e fortalece a garantia do direito à saúde.

O Projeto Mais Médicos para o Brasil apresenta-se sob a ótica de sua juridicidade como instrumento de conformação entre a primazia do princípio da universalidade do SUS, que clama a tutela do direito à saúde de populações desassistidas de cobertura médica, com o princípio da garantia do recurso humano em saúde, quanto à assistência por profissional médico, e a adoção de um regime especial para atuação destes profissionais de modo a suprir a necessidade emergencial do país, ao tempo em que propulsiona a atratividade por uma mais adequada e aprofundada formação no campo da Atenção Básica em saúde. 
O indicativo da constitucionalidade do Projeto Mais Médicos para o Brasil assentase em essência na conformação de suas regras à principiologia constitucional pertinente ao direito à saúde e ao dever do Estado como assegurador e propulsor deste direito. Ou seja, segundo elementos da equação de Alexy (15), da garantia de princípios, conforme meios para implementação, e das regras como decisão política, segundo preponderância dos valores ínsitos aos princípios e fins objetivados. E segundo a ótica de Dworkin (16), porque reflete um anseio social das camadas mais carentes do Brasil conforme assertiva de que "os cidadãos de uma comunidade de princípios não têm por único objetivo princípios comuns, como se a uniformidade fosse tudo que desejassem, mas os melhores princípios comuns que a política seja capaz de encontrar".

É essa equação principiológica que o Poder Judiciário, como terceiro vértice a sustentar o princípio republicano e a firmar a democraticidade do Estado de Direito - que na saúde habita dentre outros, no princípio da universalidade - e como agente propulsor do equilíbrio no conflito de tais garantias e na sobreposição dos fins coletivos tem ao enfrentar o julgamento das ADINs 5035 e 5037.

\section{Referências}

1 Organização Mundial de Saúde. World Health Statistics 2012. Genebra: 2012. [Acesso em 23 set 2015]. Disponível em: http://www.who.int/gho/publications/world_health_statistics/2012/en/

2 Conselho Federal de Medicina. Demografia Médica no Brasil. Brasil: 2011. [Acesso em 23 set 2015]. Disponível em:

http://portal.cfm.org.br/index.php?option=com content\&id=22508 e http://portal.cfm.org.br/images/stories/pdf/demografiamedicanobrasil vol2.pdf

3 Brasil. Ministério da Saúde. Conselho Nacional de Saúde. Resolução № 439, de 07 de abril de 2011. Diário Oficial da União. Brasília, 02 de maio 2011. [Acesso em 23 set 2015]. Disponível em:http://bvsms.saude.gov.br/bvs/saudelegis/cns/2011/res0439_07_04_2011.htm

4 Instituto de Pesquisas Aplicadas. Sistema de Indicadores de Percepção Social do SUS. Brasília: 2011. [Acesso em 08 nov 2015]. Disponível em: http://www.ipea.gov.br/portal/images/stories/PDFs/SIPS/110207 sipssaude.pdf

5 Pinto HA, Sales MJT, de Oliveira FP, Brizolara R, de Figueiredo AM, dos Santos JT. O Programa Mais Médicos e o fortalecimento da Atenção Básica. Divulgação em Saúde para Debate. Rio de janeiro, n. 51, out 2014, p. 105-120. 
6 Brasil. Senado Federal. Medida Provisória n. 261, de 8 de julho de 2013. Institui o Programa Mais Médicos e dá outras providências. Diário Oficial da União. Brasilia, 09 jul 2013. [Acesso em 23 set 2015]. Disponível em: http://legis.senado.leg.br/mateweb/arquivos/mate-pdf/132035.pdf

7 Lei n. 12.871, de 22 de outubro de 2013. Institui o Programa Mais Médicos, altera as Leis $n^{\circ} 8.745$, de 9 de dezembro de 1983, e no 6.932, de 7 de julho de 1981, e dá outras providências. Diário Oficial da União. Brasilia, 23 out 2013. [Acesso em 23 set 2015]. Disponível em: http:/www.planalto.gov.br/ccivil 03/ ato20112014/2013/Lei/L12871.htm

8 . Ministério da Saúde. Portaria Interministerial GM/MS/MEC o 1.369, de 8 de julho de 2013. Dispõe sobre a implementação do Projeto Mais Médicos para o Brasil. Diário Oficial da União. Brasilia, 09 jul 2013. [Acesso em 23 set 2015]. Disponível em: http://bvsms.saude.gov.br/bvs/saudelegis/gm/2013/pri1369_08_07_2013.html

9 Organização Mundial de Saúde. WHO Global Code of Practice on the International Recruitment of Health Personnel. Genebra: 2011. [Acesso em 23 set 2015]. Disponível em: http://www.paho.org/bra/index.php?option=com_content\& view=article\&id=1239:omsaprova-codigo-pratica-recrutamento-internacional-profissionais-saude \& Itemid=381

10 Brasil. Ministério da Saúde. Portaria n. 1.377/GM/MS, de 13 de junho de 2011. Estabelece critérios para definição das áreas e regiões prioritárias com carência e dificuldade de retenção de médico integrante de equipe de saúde da família oficialmente cadastrada e das especialidades medicas prioritárias de que tratam o inciso II e $\S 3^{\circ}$ do art. 6으 da Lei o 10.260, de 12 de julho de 2001 no âmbito do Fundo de Financiamento Estudantil (FIES) e dá outras providências. Brasília. [Acesso em 20 nov 2015].

Disponível em:

http://bvsms.saude.gov.br/bvs/saudelegis/gm/2011/prt1377_13_06_2011.html

11 . Ministério da Saúde. Sistema Cadastro Nacional de Estabelecimentos de Saúde. Brasília. [Acesso em 20 nov 2015]. Disponível em: http://cnes.datasus.gov.br/

12 Molina J, Suárez J, Cannon LRC, Oliveira G, Fortunato MA. O Programa Mais Médicos e as Redes de Atenção à Saúde no Brasil. Divulgação em Saúde para Debate. Rio de Janeiro, n. 52, out 2014, p. 190-201.

13 Brasil. Supremo Tribunal Federal. Ação Direta de Inconstitucionalidade n. 5035/DF. Requerentes: Associação Médica Brasileira-AMBr e Conselho Federal de MedicinaCFM. Requeridos: Presidente da República, Presidente da Câmara dos Deputados, Presidente do Senado Federal. Relator: Ministro Marco Aurélio de Melo. Brasilia, 23 ago 2013. [Acesso em 03 out 2015]. Disponível em: http:www.stf.jus.b r/consultaprocessual

14 Supremo Tribunal Federal. Ação Direta de Inconstitucionalidade n. 5037/DF. Requerente: Confederação nacional dos Trabalhadores Liberais Universitários Regulamentados-CNTU. Requeridos: Presidente da República e Congresso Nacional. Relator: Ministro Marco Aurélio de Melo. Brasilia, 23 ago 2013. [Acesso em 03 out 2015]. Disponível em: http:www.stf.jus.br/consultaprocessual 
15 Alexy, R. Teoria dos Direitos Fundamentais. $2^{2}$ ed. Virgílio Afonso da Silva (trad) São Paulo: Malheiros; 2011.

16 Dworkin, R. Levando os Direitos a Sério. 3ª ed. São Paulo: Martins Fontes; 2011. Nelson Boeira (trad).

17 Brasil. Advocacia Geral da União. Manifestação da Advocacia Geral da União na ADI 5035. Brasília, 27 set 2013. [Acesso em 03 out 2015]. Disponível em:

www.agu.gov.br/page/download/index/id/17842206

18 . Câmara dos Deputados. Consultoria Legislativa. Nota Descritiva da Medida Provisória n. 621, de 2013. Brasília, 8 jul 2013. [Acesso em 20 nov 2015]. Disponível em: file://C:/Users/Janaina/Downloads/2013_16632-1\%20(1).pdf

19 Senado Federal. Consultoria Legislativa. Parecer n. 53, de 2013 CN.

Brasília, 01 out 2013. [Acesso em 20 nov 2015]. Disponível em: http://legis.senado.leg.br/diarios/BuscaDiario?tipDiario=1\&datDiario=02/10/2013\&pagina Direta $=68294$

20 _. Procuradoria Geral da República. Parecer no 3451/2014-

ASJCONST/SAJ/PGR e Parecer n 3452/2014-ASJCONST/SAJ/PGR. ADIN's 5035-DF e 5037-DF. Brasilia, 28 maio 2014. [Acesso em 03 out 2015]. Disponível em: http://www.stf.jus.br/portal/processo/verProcessoA ndamento.asp?incidente $=4453685$

21 Organização das Nações Unidas. Declaração Universal dos Direitos Humanos. Paris, 10 dez 1948. [Acesso em 03 out 2015]. Disponível em: http://www.dudh.org.br/declaracao/

22 Brasil. Constituição da República Federativa do Brasil de 1988, 5 de outubro de 1988. Diário Oficial da União. Brasília, 6 out 1988. [Acesso em 23 set 2015]. Disponível em: http://www.planalto.gov.br/ccivil_03/constituicao/ConstituicaoCompilado.htm

23 Organização Mundial de Saúde. Declaracion de Alma-Ata de 1978. Ex-URSS: 1978. [Acesso em 15 out 2015]. Disponível em:

http://cmdss2011.org/site/wpcontent/uploads/2011/07/Declara\%C3\%A7\%C3\%A3oAlma-Ata.pdf

24 . Cooperação Sul-Sul. Washignton: 2010. [Acesso em 15 out 2015]. Disponível em: http://www.abc.gov.br/Projetos/CooperacaoSulSul/Cuba

25 Brasil. Decreto legislativo n. 11, de 23 de fevereiro de 1956. Aprova o Convênio Básico entre o Brasil e a Organização Mundial de Saúde para Assistência Técnica de Caráter Consultivo. Brasilia. [Acesso em 15 nov 2015]. Disponível em: http://www2.camara.leg.br/legin/fed/decleg/1950-1959/decretolegislativo-11-23-fevereiro1956-351098-publicacaooriginal-1-pl.html

26 Decreto n. 3.594, de 8 de setembro de 2000. Dispõe sobre a execução do Ajuste Complementar ao Convênio Básico entre o Governo da República Federativa do Brasil e a Organização Mundial da Saúde e ao Acordo entre o Governo da República 
Cuadernos Iberomericanos

de Derecho Sanitario

Federativa do Brasil e a Repartição Sanitária Pan-Americana para o Funcionamento do Escritório de Área da organização Pan-Americana da Saúde/Organização Mundial da Saúde no Brasil, de 16 de março de 2000. Brasilia. [Acesso em 15 nov 2015]. Disponível em: http://www.planalto.gov.br/ccivil_03/decreto/D3594.htm

Como citar este artigo:

Cerqueira JP, Alves SMC. A Constitucionalidade do Projeto Mais Médicos para o Brasil. Revista Cadernos Ibero-Americanos de Direito Sanitário. 2016 abr./jun, 5(2):92-108 